
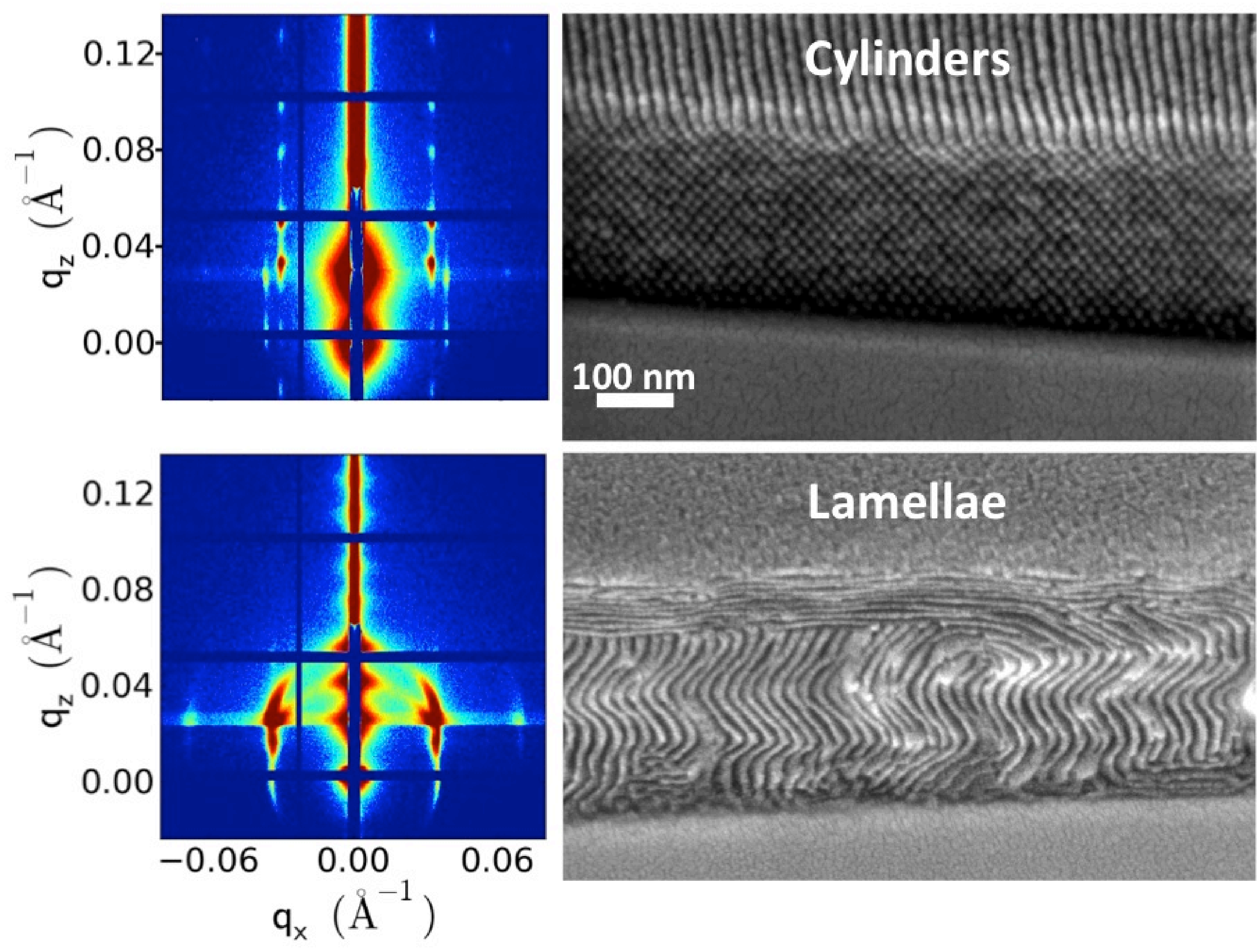


\title{
In Situ GISAXS Study of a Si-containing block copolymer under solvent vapor annealing: effects of molecular weight and solvent vapor composition
}

\author{
W. Bai ${ }^{1}$, K. G. Yager ${ }^{2}$, C. A. Ross ${ }^{1, \#}$ \\ ${ }^{1}$ Dept. Materials Science and Engineering, Massachusetts Institute of Technology, Cambridge MA 02139 \\ ${ }^{2}$ Center for Functional Nanomaterials, Brookhaven National Laboratory, Upton, NY 11973 \\ \#caross@mit.edu
}

\begin{abstract}
The room-temperature solvent vapor annealing of polystyrene- $b$-polydimethylsiloxane (PS- $b$-PDMS) block copolymer films was studied in situ by grazing incidence small-angle X-ray scattering. Films of cylinder-forming PS- $b$-PDMS with molecular weight $16 \mathrm{~kg} / \mathrm{mol}$ and $12.2 \mathrm{~kg} / \mathrm{mol}$, annealed under vapors of toluene: heptane with varying composition, exhibited swelling-ratio-dependent evolution of microdomain spacing and orientation. In a vapor made from a toluene: heptane 5:1 volumetric ratio liquid mixture, or from pure toluene, cylindrical microdomains reoriented from majority out-of-plane to in-plane during annealing, while drying led to shrinkage along the film normal and a large distortion of the hexagonal lattice of in-plane cylinders. Annealing under vapor from a toluene: heptane 1:5 volumetric ratio liquid produced a non-bulk lamellar structure in the $16 \mathrm{~kg} / \mathrm{mol}$ PS- $b$-PDMS.
\end{abstract}

\section{Introduction}

The nanoscale morphology resulting from microphase separation of a block copolymer (BCP) is determined not only by the chemistry and molecular architecture but also by the annealing environment. ${ }^{1-4}$ Annealing conditions, such as temperature, solvent vapor, ${ }^{5-8}$ electric field, ${ }^{9}$ or magnetic field, ${ }^{10}$ as well as substrate chemistry and patterning ${ }^{11-13}$ can alter the morphology and orientation of the microdomains, with implications for the use of BCPs in nanolithography and nanotechnology.

Solvent vapor annealing is an efficient method to order BCPs with high molecular weight, high block incompatibility (i.e. high Flory-Huggins parameter $\chi$ ) or with rigid rod blocks. ${ }^{7,14}$ Solvent incorporation into BCPs reduces the entanglement of polymer chains, screens unfavorable block-block interactions, and lowers the glass transition temperature, increasing the rate of microphase separation from the disordered state. Solvents induce film swelling on a macroscopic scale, and on the nanoscale can cause reorientation of the microdomains and changes in the lattice parameters. ${ }^{8,15}$ Depending on its relative solubility in each block of the $\mathrm{BCP}$, a solvent can be neutral, in which case it swells each block equally, or 
selective, in which it preferentially swells one of the blocks. ${ }^{16}$ For neutral solvent vapor annealing, the whole system is swelled and the effective volume fraction of the blocks remains unchanged, ${ }^{17}$ but selective solvent vapor annealing changes the effective volume fraction, even inducing a change of morphology or an order-order transformation, ${ }^{2,}{ }^{18}$ enabling a wide variety of morphologies to be obtained by tuning the solvent or mixture of solvents during annealing. ${ }^{4,19,20}$ Once the BCP has formed a well-defined morphology in the swollen state, further changes in solvent environment can lead to changes in the morphology, lattice dimension, or disordering. ${ }^{21-25}$ Solvent desorption results in deswelling and kinetically traps the self-assembled structure. ${ }^{8,26,27}$ Therefore, the structural evolution depends on the deswelling process as well as on the solvent environment during annealing.

It is helpful to visualize in situ how these conditions affect the self-assembly behavior in order to best control and optimize the annealing process. Grazing incidence small angle X-ray scattering (GISAXS) can quantify the nanostructure within a BCP film with little damage, ${ }^{28-32}$ and it has been successfully applied to observe morphological evolution in block copolymer films undergoing solvent vapor annealing., ${ }^{2,8,33-35}$ Evolution of microphase separation and microdomain spacing have been tracked in situ by GISAXS during solvent vapor annealing of several BCPs such as a cylinder-forming polystyrene-block-poly(2vinylpyridine) (PS- $b$-P2VP) with number average molecular weight $\mathrm{M}_{\mathrm{n}}=51 \mathrm{~kg} / \mathrm{mol}$, and $90 \mathrm{~kg} / \mathrm{mol},{ }^{8,36}$ a 24 $\mathrm{kg} / \mathrm{mol}$ sphere-forming polystyrene-block-poly(4-vinylpridine) (PS- $b$-P4VP), ${ }^{22}$ a $28 \mathrm{~kg} / \mathrm{mol}$ lamellarforming polystyrene-block-polybutadiene (PS- $b$-PB), ${ }^{34}$ and a $16 \mathrm{~kg} / \mathrm{mol}$ cylinder-forming polystyreneblock-polydimethysiloxane (PS- $b$-PDMS). ${ }^{26}$ The choice of solvents (solubility, selectivity), solvent vapor pressure, and processing history (swelling rate, drying rate, annealing time) were found to influence the $\mathrm{BCP}$ self-assembly and the final morphology. Domain spacing increased in PS- $b$-P4VP, PS- $b$-PB and PS- $b$ PDMS with absorption of a toluene:THF (tetrahydrofuran) mixture, ${ }^{22}$ ethyl acetate, ${ }^{34}$ and tolueneheptane mixture, ${ }^{26}$ respectively, while it decreased in PS-b-P2VP with absorption of THF. ${ }^{8,37}$

The solvent anneal process, including relevant surface energies, also affects the preferred orientation of the microdomains. ${ }^{22,24,27,38}$ The orientation of cylindrical microdomains in a PS- $b$-P4VP BCP thin film was in-plane (parallel to the substrate) after annealing under a nonselective vapor of chloroform, in which sufficient solvent absorption produced a disordered state and subsequent solvent drying resulted in the in-plane orientation. In contrast, cylinders formed with out-of-plane orientation after annealing under 1,4-dioxane, a selective solvent, in which a BCC spherical morphology formed in the swollen state and subsequent drying led to cylinders. ${ }^{24}$ In thin films, preferential wetting by one block at the top and bottom surfaces favored the in-plane orientation of lamellae in PS- $b$-PB ${ }^{34,39}$ and cylinders in PS- $b$ $\mathrm{PDMS}^{26}{ }^{26}$ while solvent gradients were believed to promote out-of-plane orientation of cylinders in PS- $b$ PDMS for thick films where surface interactions were less important. ${ }^{26}$ Structural transitions induced by the absorption of selective solvents were also studied in situ by GISAXS in a cylinder-forming poly( $\alpha$ methylstyrene)-block-poly(4-hydroxystyrene) (PaMS- $b$-PHOST), ${ }^{33}$ a lamellar-forming poly(2hydroxyethyl methacrylate)-block-poly(methyl methacrylate) (PHEMA-b-PMMA), ${ }^{3}$ and a cylinderforming poly(styrene)-block-poly(lactide) (PS-b-PLA). ${ }^{40}$

In this article we describe the as-cast structure and in situ morphological evolution during solvent annealing of PS- $b$-PDMS with a low molecular weight $M_{n}=12.2 \mathrm{~kg} / \mathrm{mol}$, leading to formation of microdomains with periods smaller than those examined previously by in situ GISAXS. We also examine the effect of toluene:heptane ratio on microphase separation and lattice distortion in $16 \mathrm{~kg} / \mathrm{mol}$ PS- $b$ PDMS. This work extends our earlier study of solvent annealed PS- $b$-PDMS ${ }^{26}$ in which the effects of both BCP film thickness and toluene:heptane vapor pressure at fixed vapor composition were described. 


\section{Experimental Methods}

\section{Materials}

Two cylinder-forming PS- $b$-PDMS BCPs with $\mathrm{M}_{\mathrm{n}}=16 \mathrm{~kg} / \mathrm{mol}$ (SD16) (volume fraction $f_{\mathrm{PDMS}}=0.31$, and PDI $\sim 1.08$, Polymer Source, Inc) and $12.2 \mathrm{~kg} / \mathrm{mol}$ (SD12) (volume fraction $f_{\mathrm{PDMS}}=0.30$, and PDI $\sim 1.11$, Polymer Source, Inc) were used here. Size exclusion chromatography (supplementary information) confirmed the molecular weight of SD12 as $12.2 \mathrm{~kg} / \mathrm{mol}$, with a slight bimodal distribution. In bulk, SD16 and SD12 form a hexagonally packed cylindrical morphology with periodicity $18 \mathrm{~nm}$ and $13 \mathrm{~nm}$, respectively. PS- $b$ PDMS has Flory-Huggins parameter $\chi=0.14$ or 0.26 at room temperature, ${ }^{41,42}$ sufficiently high that microphase separation can occur at room temperature even for $M_{n}$ below $10 \mathrm{~kg} / \mathrm{mol} .{ }^{43}$ PS- $b$-PDMS has high etch resistance and etch selectivity in an oxygen plasma, which can remove the PS block and partially oxidize the PDMS block into rigid $\mathrm{SiO}_{x}{ }^{44}$ enabling the morphology to be imaged post-anneal.

SD12 and SD16 were spin coated on silicon substrates from $5 \mathrm{wt} \%$ solution in toluene to form films of 200-400 nm thickness. The solution concentration and spin speed were adjusted to control the as-cast film thickness. Samples were processed by annealing in a solvent vapor from a toluene and heptane liquid mixture at room temperature.

\section{In Situ GISAXS during solvent annealing}

A customized solvent annealing chamber was placed in the synchrotron GISAXS beamline (X9 beamline, National Synchrotron Light Source, Brookhaven National Laboratory). Three tubes were connected to the annealing chamber: one is to inject liquid solvent, typically $10 \mathrm{ml}$, from an external solvent reservoir directly into a small solvent reservoir inside the annealing chamber, one is to inject pure nitrogen, and the last one is to collect vapor exhaust. The annealing chamber includes a small stage to support the sample and a reservoir beside it to contain the injected liquid solvent, allowing evaporated solvent vapor to reach the sample and avoiding immersion of the sample in the liquid solvent. All experiments were carried at room temperature. The solvent vapor pressure was tuned by controlling the amount of liquid solvent injected initially, and the nitrogen flow into the annealing chamber. The flow rate was 10 sccm. The partial vapor pressure of toluene and heptane was estimated (Table S1) based on the size of the annealing chamber, the amount of liquid solvent added, and assuming the solvent vapor leakage rate is constant. ${ }^{4,19}$ The injection of pure nitrogen is to dilute the solvent vapor and control the solvent desorption from the swelled film. All the solvent annealing processes were conducted within $60 \mathrm{~min}$ total annealing time at room temperature, in which only a small amount ( $<5 \%$ of the total volume) of the liquid solvent was evaporated during the annealing process. Therefore, the solvent vapor pressure can be treated as constant at steady state for a given amount of liquid solvent in the chamber and nitrogen flow rate. For all experiments described here, the drying was carried out in two steps, which correspond to the two stages of deswelling in the plots of swelling ratio vs. time (Figure 2): first, nitrogen purged into the annealing chamber at $100 \mathrm{sccm}$ for 7-10 mins, then the flow speed was increased to $200 \mathrm{sccm}$ for 7-10 mins. The lid of the annealing chamber was finally opened to complete the drying of the samples. 
The customized solvent annealing chamber, with volume $\sim 900 \mathrm{ml}$, has two kapton windows on the front and back, in order to allow the incident X-rays beam to impinge on the sample, and for the $\mathrm{x}$-ray scattering originating from the sample to exit. The two-dimensional scattering data were collected by either a charge-coupled device detector (MarCCD), or a hybrid pixel-array detector (Dectris Pilatus 1M). The sample chamber features a quartz window on the top lid, in order to allow the transmission of a UVvisible beam from a Filmetrics spectral reflectometer (F20-UV, 250-1500 nm) for in situ film thickness measurement to determine swelling ratio. In order to avoid beam damage from the X-ray exposure, the GISAXS measurement moved to a fresh spot of the film after every two measurements (X-ray exposures were limited to $10 \mathrm{~s}$ ). More details of the experimental setup can be found in our previous report. ${ }^{26}$ The lattice constants of the BCP hexagonal unit-cell or lamellae were obtained from the GISAXS data as

described previously. ${ }^{26}$ The lattice distortion of an array of in-plane cylinders was defined as $D F=\frac{2 H_{Z}}{\sqrt{3} H_{X}}$, where $\mathrm{H}_{\mathrm{z}}$ is the out-of-plane distance between layers of cylinders and $\mathrm{H}_{\mathrm{X}}$ is the center-to-center distance within a layer of cylinders. For ideally close-packed cylinders $H_{z} / H_{x}=\sqrt{ } 3 / 2$ and $D F=1$. For cylinders oriented out of plane, $\mathrm{Px}_{\mathrm{x}}$ is the center-to-center distance. For in-plane lamellae (aligned parallel to the substrate) and out-of-plane lamellae (standing perpendicular to the substrate), the spacing is $L_{z}$ and $L_{x}$ respectively.

\section{Selective etching of microdomain morphology}

After annealing, a thin PDMS wetting layer was present at the air/film interface because of the lower surface energy of the PDMS block. This was removed by a short $\mathrm{CF}_{4}$ reactive ion etch (power $60 \mathrm{~W}$, pressure $15 \mathrm{mTorr}$, gas flow speed $10 \mathrm{sccm}$, Plasma-Therm 790). ${ }^{4} \mathrm{An} \mathrm{O}_{2}$ plasma (90W, $6 \mathrm{mTorr}, 10 \mathrm{sccm}$ ) was used to remove the PS microdomains by conversion into $\mathrm{CO}_{2}$ and $\mathrm{H}_{2} \mathrm{O}$ vapor, and partially oxidized the PDMS microdomains into a robust silica-rich nanopattern, which was imaged by scanning electron microscopy. Cross-section images were prepared by cracking the sample after cooling in liquid nitrogen followed by reactive ion etching of the cracked edge, and imaged after tilting the sample $70^{\circ}$ to the SEM detector in order to show the morphology of both top and cross-section surface.

\section{Results and Discussion}

Results from four annealing processes are analyzed. In Process (i) a $210 \mathrm{~nm}$-thick SD16 film was annealed under a pure toluene vapor, in Process (ii) a $231 \mathrm{~nm}$-thick SD16 film was annealed under a vapor from a toluene:heptane 5:1 volumetric mixture, in Process (iii) a $208 \mathrm{~nm}$-thick SD12 film was annealed under a vapor from a toluene:heptane 5:1 volumetric mixture, and in Process (iv) a $400 \mathrm{~nm}$ thick SD16 film was annealed under vapor from a toluene:heptane 1:5 mixture. Fig. 1 shows the final morphologies, Fig. 2 gives the corresponding swelling ratios and Fig. 3 gives selected in situ GISAXS data. Figs. 4-5 present an analysis of the geometry of the microdomain arrays. Processes (i-iii) yielded cylindrical morphologies whereas Process (iv) yielded lamellae. The effect of annealing process and molecular weight on the period, orientation and distortion factor [see Methods section for definition] of the microdomains will be described in the following paragraphs.

\section{a. Structure and period of as-cast films}


For the as-cast SD16 and SD12 films, the spin-cast film consisted of a poorly-ordered micellar morphology. ${ }^{26}$ The disorder caused a smearing of the Bragg intensities, which resulted in broad peaks spreading out well into reciprocal space (Fig. 2b\&c, left panels). The scattering intensity formed an arc indicating that nearest neighbor as-cast micelles were oriented in a range of directions, and the spacing in the out-of-plane direction was $3 \mathrm{~nm}$ smaller than in-plane direction, represented by the elongated scattering peak along the $\mathrm{q}_{\mathrm{z}}$ direction. In the film plane, the period of the micellar structures of as-cast SD16 and SD12 films were $16 \mathrm{~nm}$ and $12 \mathrm{~nm}$, respectively, with standard error $3 \mathrm{~nm}$. For these films, spin coating led to rapid solvent evaporation at room temperature, yielding a kinetically trapped micellar state, unlike spin coating at higher temperatures which can form a well-ordered as-cast morphology. ${ }^{45}$

\section{b. Effect of toluene: heptane solvent composition on morphology and lattice distortion}

We first examine the effect of composition of the solvent vapor on the morphology of SD16 by altering the composition of the $10 \mathrm{ml}$ liquid solvent mixture added to the chamber. Fig. 2a,b,d compares SD16 films under Process (i) which used pure toluene, Process (ii) which used a toluene: heptane 5:1 volumetric mixture and Process (iv) which used a toluene: heptane 1:5 volumetric mixture. Process (ii) resulted in a higher swelling ratio. Neither toluene nor heptane is a neutral solvent for PS-PDMS: heptane preferentially swells PDMS whereas toluene can swell both blocks but swells PS more. ${ }^{19}$ However the toluene: heptane 5:1 volumetric mixture has been found to approximate a neutral solvent for cylinder-forming PS-PDMS films, ${ }^{19,26,46}$ leading to similar swelling of both PS and PDMS blocks.

Processes (i) and (ii) produced cylindrical morphologies as seen in bulk. When the films were in the swollen state, cylindrical microdomains were present with their axes oriented in both out-of-plane and in-plane directions according to the GISAXS data of Fig. 3. As shown in Fig. 4a, in the initial stage (0-2 $\mathrm{min}$ ) of annealing the SD16 the out-of-plane self-assembled cylinders formed the majority (around 87\% of the total volume of cylinders) with a small portion of cylinders in-plane and in other directions. The perpendicular cylinder orientation was assumed to be caused by the solvent concentration gradient during swelling. ${ }^{6,47-49}$ Between $2 \mathrm{~min}$ and $15 \mathrm{~min}$, the fraction of in-plane cylinders increased from $8 \%$ to $80 \%$ for Process (i), and from $8 \%$ to $90 \%$ for Process (ii), and remained at that value throughout the anneal. During drying there was a slight decrease of the fraction of in-plane cylinders. In some other cases of solvent annealing, the BCP was disordered in the swollen state (i.e. driven through the orderdisorder transition) and solvent evaporation resulted in an ordering front propagating through the entire film. ${ }^{49}$ However, in the process used here, the films remained ordered and microphase separated even in the swollen state.

Based on the position of the scattering peaks, the spacing of in-plane (Fig. $\mathbf{4 b , c}$ ) and out-of-plane (Fig. 4e) cylindrical microdomains were quantified in situ. For out-of-plane cylinders, after an initial increase, the center-to-center distance $P_{x}$ showed little variation throughout the solvent anneal. Solvent evaporation did not induce a clear change in $P_{x}$ either, i.e. during drying the lattice of cylinders shrank in the out-ofplane direction but its in-plane spacing did not change systematically.

Considering the in-plane cylinders, in the swollen state the lattice spacing $\left(\mathrm{H}_{\mathrm{x}}\right.$ and $\left.\mathrm{H}_{\mathrm{z}}\right)$ remained approximately constant except for the first data point for $\mathrm{H}_{\mathrm{z}}$ at $13.8 \mathrm{~min}$ for process (i), which may have differed because of realignment of the $\mathrm{X}$-ray beam. However, solvent removal during drying collapsed 
the film in the out-of-plane direction $\mathrm{H}_{\mathrm{z}}$ and induced a significant lattice distortion. More specifically, drying led to a slight increase in the in-plane spacing $\mathrm{H}_{\mathrm{x}}$ (by $1 \mathrm{~nm}$ for both processes), but there was a much larger decrease in the out-of-plane spacing $\mathrm{H}_{2}$ (by $\sim 2-7 \mathrm{~nm}$ for process (i) and $5 \mathrm{~nm}$ for process (ii)), as the film volume was reduced. As a result, the lattice of cylindrical microdomains, which in the swelled state was hexagonally closepacked (its distortion factor $D F=\frac{2 H_{Z}}{\sqrt{3} H_{X}}$ was close to 1 for process (ii) and varied around 1 for process (i)), became compressed in the out-of-plane direction, Fig. 4d. The final DF after processes (i) and (ii) was 0.85 and 0.75 , respectively. Hence, the self-assembled morphology in the swelled state has the same spacing in-plane and out-of plane, while deswelling led to an anisotropic structure due to a collapse along the out-of-plane direction and almost invariant in-plane spacing. Process (ii) had a higher saturated swelling ratio of 1.56 compared to 1.47 for process (i), therefore there was a greater reduction in volume on drying, which corresponds to the higher degree of lattice distortion.

The large change in out-of-plane period $\mathrm{H}_{\mathrm{z}}$ and distortion factor of the microdomain array, and the small changes in in-plane period $\mathrm{H}_{\mathrm{x}}$ and $\mathrm{P}_{\mathrm{x}}$ during annealing and drying are similar to those discussed in Ref. 26. Using the same approximation as Ref. 26 the effective $\chi \mathrm{N}$ (where $\mathrm{N}$ is the degree of polymerization of the $\mathrm{BCP}$ ) at a swelling ratio of 1.50 is around 25.5, which is consistent with the GISAXS observation that the system was still within the strong segregation regime during the entire annealing process. ${ }^{50}$ Small changes in the in-plane period on drying were attributed ${ }^{26}$ to the change in $\chi_{\text {eff }}=\chi\left(1-f_{s}\right)^{n}$ where $f_{s}$ is the fraction of solvent in the solvent/BCP system and $\mathrm{n}$ is a dilution parameter that depends on the solvent concentration. ${ }^{17,51}$

To illustrate a solvent-driven morphology change, we now discuss Process (iv) in which a vapor from a toluene: heptane 5:1 volumetric mixture was used. Unlike Processes (i) and (ii), Process (iv) produced a lamellar morphology because the higher heptane content of the vapor preferentially swelled the PDMS block and increased its volume fraction. Similar to the cylinders in Process (ii), a lamellar morphology was evident at 2 min anneal, Fig. 3d. The lamellar microdomains are initially orientationally disordered, as evidenced by the nearly-uniform scattering intensity along the observed arcs. As annealing proceeds, the orientation distribution becomes sharper, consistent with a bimodal population of two lamellae orientations (in-plane and out-of-plane). The relative position of the higher-order peaks is indicative of a lamellar morphology. Unlike Processes (i)-(iii) where the majority of cylinders were oriented either inplane or out-of-plane as the swelling ratio approached saturation, the lamellae in process (iv) still exhibited a broad orientation distribution (nearly isotropic) even when the swelling ratio reached saturation (Fig. 3d3). Thereafter, the intensity of scattering peaks corresponding to in-plane and out-ofplane lamellae gradually increased (Fig. 3d3\&3d4), indicating that fractions of both in-plane and out-ofplane lamellae increased as annealing proceeded, at the expense of the isotropic population. The significant fraction of randomly oriented lamellae precluded quantitative calculation of the fractions of IP and OP lamellae, but the GISAXS data shows qualitatively that the lamellae gradually converted from OP-majority to IP majority during annealing. Drying produced cooperatively tilted lamellae as the film volume was reduced as shown in the SEM of the final morphology, Fig. 1d. The formation of the nonbulk morphology of the SD16 film was due to the shift of effective volume fraction induced by selective 
swelling, and the SD12 film with lower molecular weight but similar volume fraction is expected to follow a similar morphology transition under the same selective swelling conditions.

The period of in-plane and out-of-plane oriented lamellae evolved during the solvent annealing process as shown in Fig. 5. For lamellae oriented out-of-plane, the period $L_{x}$ varied throughout the anneal. Swelling within the first 15 minutes (Fig. 5b) increased the total volume of the film by $29 \%$ and its period $L_{x}$ from $17.2 \mathrm{~nm}$ to $19.2 \mathrm{~nm}$. Then as swelling approached saturation, $L_{x}$ decreased from $19.2 \mathrm{~nm}$ to $18.2 \mathrm{~nm}$ which is possibly caused by the decrease of effective $\chi$. Deswelling resulted in a slight increase in $L_{x}$, possibly a result of the tilting of the perpendicular lamellae as the film shrank as shown in the SEM, Fig. 1d. For lamellae oriented in-plane, the trend of period $L_{z}$ varied similarly with period $L_{x}$ during the annealing except deswelling caused a decrease in $L_{z}$ (from $18.1 \mathrm{~nm}$, before deswelling, to $14.8 \mathrm{~nm}$, final dry state, Fig. $\mathbf{5 b}$ ) analogous to the decrease in $\mathrm{H}_{\mathrm{z}}$ for in-plane cylinders in Fig. $\mathbf{4 b}$. To compare with the distortion factor used in describing the lattice distortion of in-plane cylinders (Fig. 4d), $\mathrm{L}_{z} / \mathrm{L}_{\mathrm{x}}$ is plotted in Fig. $\mathbf{5 c}$ to show the lamellar structure distortion. Within the first 5 min of swelling, $\mathrm{L}_{z}$ was larger than $L_{x}$, which is caused by the rapid film volume increase along the out of plane direction. At the saturated swelling state, $L_{x}$ was slightly larger than $L_{z}$, and deswelling exacerbated the difference so that $L_{z} / L_{x}$ dropped from 0.94 to 0.79 .

\section{c. Comparison of morphological evolution of SD12 and SD16}

We examined the evolution of the structure of SD12 in toluene: heptane vapor from a 5:1 volumetric mixture, Figs. 2a, 3c and 4. The SD12 film, Process (iii), exhibited a lower saturated swelling ratio than the SD16 film annealed under the same conditions, Process (ii). In both polymers, well-defined cylindrical morphologies were first observed within a few minutes of solvent annealing. As annealing proceeded the cylinders reoriented from mainly out-of-plane to $90 \%$ of cylinders in-plane, and the ordering improved (as shown by correlation length, Fig. 4e). The SD12 film reoriented to in-plane cylinders 6 min faster than the SD16 film did; since the film thickness and the vapor environment were the same, this is indicative of a higher diffusivity as expected from the shorter chain length. But even the longest correlation length for SD12 (process (iii)) was still lower than that of SD16 (process (ii)), considering that the annealing conditions were the same. It possibly resulted from the larger PDI of SD12 and its bimodal distribution in molecular weight (Fig. S1 of supplementary material). In all of the processes (i)-(iii), deswelling decreased the correlation length and the degree of ordering (Fig. 4e).

The SD12 in-plane cylinders had a constant in-plane period $\mathrm{H}_{\mathrm{x}}=15.5 \mathrm{~nm}$ during the swelling and saturated swelling stage (Fig. 4b), while drying led to a slight increase of $\mathrm{Hx}_{\mathrm{x}}$ by $0.7 \mathrm{~nm}$. The layer spacing $\mathrm{H}_{\mathrm{z}}$ was constant $12.2 \mathrm{~nm}$ during the swelling and saturated swelling stage, but it decreased to $9.5 \mathrm{~nm}$ on drying, Fig. 4c. The center-to-center spacing of out-of-plane cylinders $P_{x}$ (Fig. 4f) was $15.7 \mathrm{~nm}$ to $15.0 \mathrm{~nm}$ in the swelled state and did not change on drying, although as seen in the SD16 data, there was an initial sharp rise in the first minute of the anneal. Overall the SD12 followed the same trends as seen in the SD16 except its period was smaller and its correlation length was shorter: the ratio $P_{x, S D 12} / P_{x, S D 16}=0.82$ which matches the ratio of $\left(\mathrm{M}_{n, S D 12} / \mathrm{M}_{\mathrm{n}, \mathrm{SD} 16}\right)^{2 / 3}$. In both SD12 and SD16 the in-plane cylinders formed a near ideal hexagonally packed symmetry in the saturated swelled state with distortion factor of 0.95 for SD12 and 1.0 for SD16, but the drying led to a reduction in DF to 0.71 and 0.78 respectively. The SD12 showed greater distortion even though its initial swelling ratio was lower possibly due to its lower 
degree of polymer chain entanglement. This confirms for the smaller $\mathrm{M}_{n} \mathrm{BCP}$ a model of film collapse in the out-of-plane direction during drying, while the in-plane period is largely preserved.

\section{Conclusions}

The progress of microphase separation during solvent vapor annealing was observed in situ by GISAXS for bulk cylinder-forming SD12 PS-PDMS with molecular weight $12.2 \mathrm{~kg} / \mathrm{mol}$ and period $13 \mathrm{~nm}$ and SD 16 with molecular weight $16 \mathrm{~kg} / \mathrm{mol}$ and period $18 \mathrm{~nm}$. This work extends an earlier study ${ }^{26}$ of SD16 by considering the effect of solvent vapor composition (toluene:heptane) and by examining a smaller molecular weight, SD12. Toluene vapor and the vapor from a 5:1 toluene:heptane volumetric liquid mixture both produced cylindrical morphologies in SD16 whereas the vapor from a 1:5 toluene:heptane mixture produced lamellae, the first in situ observation of a non-bulk morphology forming from the ascast state using a selective solvent mixture. The cylindrical microdomains were initially mainly oriented out of plane, but reoriented towards the in-plane direction in the first $10-20 \mathrm{~min}$ of the anneal. SD12 is the smallest period BCP thin film observed by in situ GISAXS, and it behaved qualitatively the same as the SD16 during annealing in the vapor from the 1:5 ratio solvent mixture, except the cylinder reorientation took place more rapidly and the correlation length was longer. A general observation for both materials and different solvent composition was that the in-plane period of the microdomains showed little variation throughout the anneal or on deswelling whereas the out of plane period decreased on drying, leading to a distorted microdomain array as the film collapsed along the out-ofplane direction.

\section{Acknowledgements}

We are gratefully for discussion and assistance from Dr. Charles Black and Benjamin Ocko of Brookhaven National Laboratory, and SEC measurement from Julia A. Kalow of Department of Chemistry, MIT. Research was carried out in part at the Center for Functional Nanomaterials and the National Synchrotron Light Source, Brookhaven National Laboratory, which are supported by the U.S. Department of Energy, Office of Basic Energy Sciences under Contract DE-SC0012704. This work was supported by Taiwan Semiconductor Manufacturing Corp., and used facilities from the MIT Center for Materials Science and Engineering (MRSEC Award DMR1419807).

\section{References}

(1) Wu, Y.; Cheng, G.; Katsov, K.; Sides, S. W.; Wang, J.; Tang, J.; Fredrickson, G. H.; Moskovits, M.; Stucky, G. D. Composite Mesostructures by Nano-Confinement. Nat. Mater. 2004, 3 (11), 816822.

(2) Paik, M. Y.; Bosworth, J. K.; Smilges, D.-M.; Schwartz, E. L.; Andre, X.; Ober, C. K. Reversible Morphology Control in Block Copolymer Films via Solvent Vapor Processing: An In Situ GISAXS Study. Macromolecules 2010, 43 (9), 4253-4260.

(3) Chavis, M. A.; Smilgies, D.-M.; Wiesner, U. B.; Ober, C. K. Widely Tunable Morphologies in Block Copolymer Thin Films Through Solvent Vapor Annealing Using Mixtures of Selective Solvents. Adv. Funct. Mater. 2015, 25 (20), 3057-3065.

(4) Bai, W.; Hannon, A. F.; Gotrik, K. W.; Choi, H. K.; Aissou, K.; Liontos, G.; Ntetsikas, K.; AlexanderKatz, A.; Avgeropoulos, A.; Ross, C. A. Thin Film Morphologies of Bulk-Gyroid Polystyrene- Block - 
Polydimethylsiloxane under Solvent Vapor Annealing. Macromolecules 2014, 47 (17), 6000-6008.

(5) Jung, Y. S.; Ross, C. A. Solvent-Vapor-Induced Tunability of Self-Assembled Block Copolymer Patterns. Adv. Mater. 2009, 21 (24), 2540-2545.

(6) Kim, E.; Kim, W.; Lee, K. H.; Ross, C. A.; Son, J. G. A Top Coat with Solvent Annealing Enables Perpendicular Orientation of Sub-10 Nm Microdomains in Si-Containing Block Copolymer Thin Films. Adv. Funct. Mater. 2014, 6981-6988.

(7) Sinturel, C.; Vayer, M.; Morris, M.; Hillmyer, M. A. Solvent Vapor Annealing of Block Polymer Thin Films. Macromolecules 2013, 46 (14), 5399-5415.

(8) Gu, X.; Gunkel, I.; Hexemer, A.; Gu, W.; Russell, T. P. An in Situ Grazing Incidence X-Ray Scattering Study of Block Copolymer Thin Films during Solvent Vapor Annealing. Adv. Mater. 2014, 26 (2), 273-281.

(9) Böker, A.; Elbs, H.; Hänsel, H.; Knoll, A.; Ludwigs, S.; Zettl, H.; Urban, V.; Abetz, V.; Müller, A. H. E.; Krausch, G. Microscopic Mechanisms of Electric-Field-Induced Alignment of Block Copolymer Microdomains. Phys. Rev. Lett. 2002, 89 (13), 135502.

(10) Majewski, P. W.; Gopinadhan, M.; Osuji, C. O. Magnetic Field Alignment of Block Copolymers and Polymer Nanocomposites: Scalable Microstructure Control in Functional Soft Materials. J. Polym. Sci. Part B Polym. Phys. 2012, 50 (1), 2-8.

(11) Stoykovich, M. P.; Müller, M.; Kim, S. O.; Solak, H. H.; Edwards, E. W.; de Pablo, J. J.; Nealey, P. F. Directed Assembly of Block Copolymer Blends into Nonregular Device-Oriented Structures. Science (80-. ). 2005, 308 (5727), 1442-1446.

(12) Gotrik, K. W.; Lam, T.; Hannon, A. F.; Bai, W.; Ding, Y.; Winterstein, J.; Alexander-Katz, A.; Liddle, J. A.; Ross, C. A. 3D TEM Tomography of Templated Bilayer Films of Block Copolymers. Adv. Funct. Mater. 2014, 24 (48), 7689-7697.

(13) Bai, W.; Gadelrab, K.; Alexander-Katz, A.; Ross, C. A. Perpendicular Block Copolymer Microdomains in High Aspect Ratio Templates. Nano Lett. 2015, 15 (10), 6901-6908.

(14) Albert, J. N. L.; Epps, T. H. Self-Assembly of Block Copolymer Thin Films. Mater. Today 2010, 13 (6), 24-33.

(15) Son, J. G.; Gotrik, K. W.; Ross, C. A. High-Aspect-Ratio Perpendicular Orientation of PS- B -PDMS Thin Films under Solvent Annealing. ACS Macro Lett. 2012, 1 (11), 1279-1284.

(16) Lodge, T. P.; Pudil, B.; Hanley, K. J. The Full Phase Behavior for Block Copolymers in Solvents of Varying Selectivity. Macromolecules 2002, 35 (12), 4707-4717.

(17) Lodge, T. P.; Hanley, K. J.; Pudil, B.; Alahapperuma, V. Phase Behavior of Block Copolymers in a Neutral Solvent. Macromolecules 2003, 36 (3), 816-822.

(18) Hanley, K. J.; Lodge, T. P.; Huang, C.-I. Phase Behavior of a Block Copolymer in Solvents of Varying Selectivity. Macromolecules 2000, 33 (16), 5918-5931.

(19) Gotrik, K. W.; Hannon, A. F.; Son, J. G.; Keller, B.; Alexander-Katz, A.; Ross, C. A. Morphology Control in Block Copolymer Films Using Mixed Solvent Vapors. ACS Nano 2012, 6 (9), 8052-8059.

(20) Stenbock-Fermor, A.; Rudov, A. A.; Gumerov, R. A.; Tsarkova, L. A.; Böker, A.; Möller, M.; Potemkin, I. I. Morphology-Controlled Kinetics of Solvent Uptake by Block Copolymer Films in Nonselective Solvent Vapors. ACS Macro Lett. 2014, 3 (8), 803-807.

(21) Hanley, K. J.; Lodge, T. P. Effect of Dilution on a Block Copolymer in the Complex Phase Window. J. 
Polym. Sci. Part B Polym. Phys. 1998, 36 (17), 3101-3113.

(22) Gunkel, I.; Gu, X.; Sun, Z.; Schaible, E.; Hexemer, A.; Russell, T. P. An in Situ GISAXS Study of Selective Solvent Vapor Annealing in Thin Block Copolymer Films: Symmetry Breaking of in-Plane Sphere Order upon Deswelling. J. Polym. Sci. Part B Polym. Phys. 2016, 54 (2), 331-338.

(23) Di, Z.; Posselt, D.; Smilgies, D.-M.; Papadakis, C. M. Structural Rearrangements in a Lamellar Diblock Copolymer Thin Film during Treatment with Saturated Solvent Vapor. Macromolecules 2010, 43, 418-427.

(24) Gowd, E. B.; Böhme, M.; Stamm, M. In Situ GISAXS Study on Solvent Vapour Induced Orientation Switching in PS- B -P4VP Block Copolymer Thin Films. IOP Conf. Ser. Mater. Sci. Eng. 2010, 14 (1), 012015.

(25) Kao, J.; Thorkelsson, K.; Bai, P.; Zhang, Z.; Sun, C.; Xu, T. Rapid Fabrication of Hierarchically Structured Supramolecular Nanocomposite Thin Films in One Minute. Nat. Commun. 2014, 5, 4053.

(26) Bai, W.; Yager, K. G.; Ross, C. A. In Situ Characterization of the Self-Assembly of a PolystyrenePolydimethylsiloxane Block Copolymer during Solvent Vapor Annealing. Macromolecules 2015, 48 (23), 8574-8584.

(27) Phillip, W. A.; Hillmyer, M. A.; Cussler, E. L. Cylinder Orientation Mechanism in Block Copolymer Thin Films Upon Solvent Evaporation. Macromolecules 2010, 43 (18), 7763-7770.

(28) Byeongdu Lee, †; Insun Park; Jinhwan Yoon; Soojin Park; Jehan Kim; Kwang-Woo Kim; Taihyun Chang, * and; Ree*, M. Structural Analysis of Block Copolymer Thin Films with Grazing Incidence Small-Angle X-Ray Scattering. Macromolecules 2005, 38 (10), 4311-4323.

(29) Lee, B.; Park, I.; Yoon, J.; Park, S.; Kim, J.; Kim, K.-W.; Chang, T.; Ree, M. Structural Analysis of Block Copolymer Thin Films with Grazing Incidence Small-Angle X-Ray Scattering. Macromolecules 2005, 38 (10), 4311-4323.

(30) Busch, P.; Posselt, D.; Smilgies, D.-M.; Rauscher, M.; Papadakis, C. M. Inner Structure of Thin Films of Lamellar Poly(styrene- B -Butadiene) Diblock Copolymers As Revealed by GrazingIncidence Small-Angle Scattering. Macromolecules 2007, 40 (3), 630-640.

(31) Hexemer, A.; Bras, W.; Glossinger, J.; Schaible, E.; Gann, E.; Kirian, R.; MacDowell, A.; Church, M.; Rude, B.; Padmore, H. A SAXS/WAXS/GISAXS Beamline with Multilayer Monochromator. J. Phys. Conf. Ser. 2010, 247 (1), 012007.

(32) Wernecke, J.; Okuda, H.; Ogawa, H.; Siewert, F.; Krumrey, M. Depth-Dependent Structural Changes in PS- B -P2VP Thin Films Induced by Annealing. Macromolecules 2014, 47 (16), 57195727.

(33) Paik, M. Y.; Bosworth, J. K.; Smilges, D.-M.; Schwartz, E. L.; Andre, X.; Ober, C. K. Reversible Morphology Control in Block Copolymer Films via Solvent Vapor Processing: An In Situ GISAXS Study. Macromolecules 2010, 43, 4253-4260.

(34) Zhang, J.; Posselt, D.; Smilgies, D.-M.; Perlich, J.; Kyriakos, K.; Jaksch, S.; Papadakis, C. M. Lamellar Diblock Copolymer Thin Films during Solvent Vapor Annealing Studied by GISAXS: Different Behavior of Parallel and Perpendicular Lamellae. Macromolecules 2014, 47 (16), 5711-5718.

(35) Di, Z.; Posselt, D.; Smilgies, D.-M.; Papadakis, C. M. Structural Rearrangements in a Lamellar Diblock Copolymer Thin Film during Treatment with Saturated Solvent Vapor. 2009.

Gu, X.; Gunkel, I.; Hexemer, A.; Russell, T. P. Controlling Domain Spacing and Grain Size in 
Cylindrical Block Copolymer Thin Films by Means of Thermal and Solvent Vapor Annealing. Macromolecules 2016, 49 (9), 3373-3381.

(37) Gu, X.; Gunkel, I.; Hexemer, A.; Russell, T. P. Solvent Vapor Annealing of Block Copolymer Thin Films: Removal of Processing History. Colloid Polym. Sci. 2014, 292 (8), 1795-1802.

(38) Paradiso, S. P.; Delaney, K. T.; García-Cervera, C. J.; Ceniceros, H. D.; Fredrickson, G. H. Block Copolymer Self Assembly during Rapid Solvent Evaporation: Insights into Cylinder Growth and Stability. ACS Macro Lett. 2014, 3 (1), 16-20.

(39) Sepe, A.; Zhang, J.; Perlich, J.; Smilgies, D.-M.; Posselt, D.; Papadakis, C. M. Toward an Equilibrium Structure in Lamellar Diblock Copolymer Thin Films Using Solvent Vapor Annealing - An in-Situ Time-Resolved GISAXS Study. Eur. Polym. J. 2015.

(40) Sinturel, C.; Grosso, D.; Boudot, M.; Amenitsch, H.; Hillmyer, M. A.; Pineau, A.; Vayer, M. Structural Transitions in Asymmetric Poly(styrene)-Block-Poly(lactide) Thin Films Induced by Solvent Vapor Exposure. ACS Appl. Mater. Interfaces 2014, 6 (15), 12146-12152.

(41) Nose, T. Coexistence Curves of Polystyrene/ Poly(dirnethylsiloxane) Blends. Polymer (Guildf). 1995, 36 (11), 2243-2248.

(42) Kennemur, J. G.; Yao, L.; Bates, F. S.; Hillmyer, M. A. Sub-5 Nm Domains in Ordered Poly(cyclohexylethylene)- Block -Poly(methyl Methacrylate) Block Polymers for Lithography. Macromolecules 2014, 47 (4), 1411-1418.

(43) Nose, T. Coexistence Curves of Polystyrene/ Poly(dimethylsiloxane) Blends. Polymer (Guildf). 1995, 36 (11), 2243-2248.

(44) Tu, K.-H.; Bai, W.; Liontos, G.; Ntetsikas, K.; Avgeropoulos, A.; Ross, C. A. Universal Pattern Transfer Methods for Metal Nanostructures by Block Copolymer Lithography. Nanotechnology 2015, 26 (37), 375301.

(45) Kim, J. M.; Kim, Y.; Park, W. I.; Hur, Y. H.; Jeong, J. W.; Sim, D. M.; Baek, K. M.; Lee, J. H.; Kim, M.J.; Jung, Y. S. Eliminating the Trade-Off between the Throughput and Pattern Quality of Sub-15 Nm Directed Self-Assembly via Warm Solvent Annealing. Adv. Funct. Mater. 2015, 25 (2), 306315.

(46) Hannon, A. F.; Bai, W.; Alexander-Katz, A.; Ross, C. A. Simulation Methods for Solvent Vapor Annealing of Block Copolymer Thin Films. Soft Matter 2015.

(47) Jeong, J.; Ha, J. S.; Lee, S.-S.; Son, J. G. Topcoat-Assisted Perpendicular and Straightly Parallel Coexisting Orientations of Block Copolymer Films. Macromol. Rapid Commun. 2015, 36 (13), 1261-1266.

(48) Sakurai, S. Progress in Control of Microdomain Orientation in Block Copolymers - Efficiencies of Various External Fields. Polymer (Guildf). 2008, 49 (12), 2781-2796.

(49) Kim, S. H.; Misner, M. J.; Xu, T.; Kimura, M.; Russell, T. P. Highly Oriented and Ordered Arrays from Block Copolymers via Solvent Evaporation. Adv. Mater. 2004, 16 (3), 226-231.

(50) Bates, F. S.; Fredrickson, G. H. Block Copolymer Thermodynamics: Theory and Experiment. Annu. Rev. Phys. Chem. 1990, 41, 525-557.

(51) Lodge, T. P.; Pan, C.; Jin, X.; Liu, Z.; Zhao, J.; Maurer, W. W.; Bates, F. S. Failure of the Dilution Approximation in Block Copolymer Solutions. J. Polym. Sci. Part B Polym. Phys. 1995, 33 (16), 2289-2293. 


\section{Figures:}
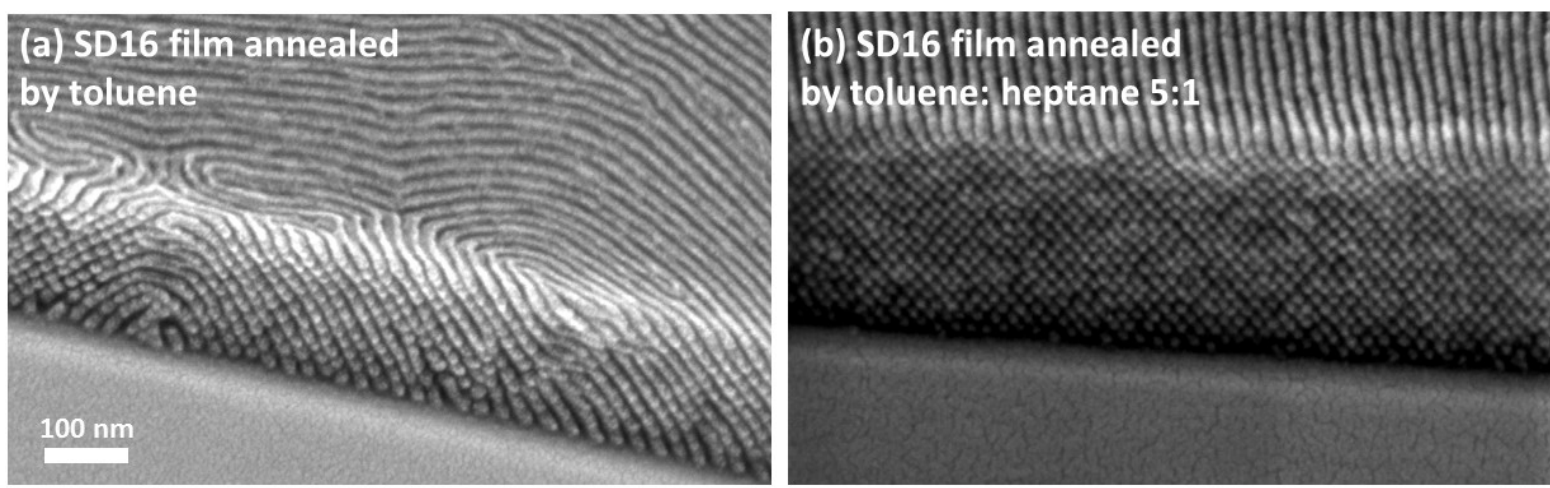

\section{(c) SD12 film annealed \\ by toluene: heptane $5: 1$}

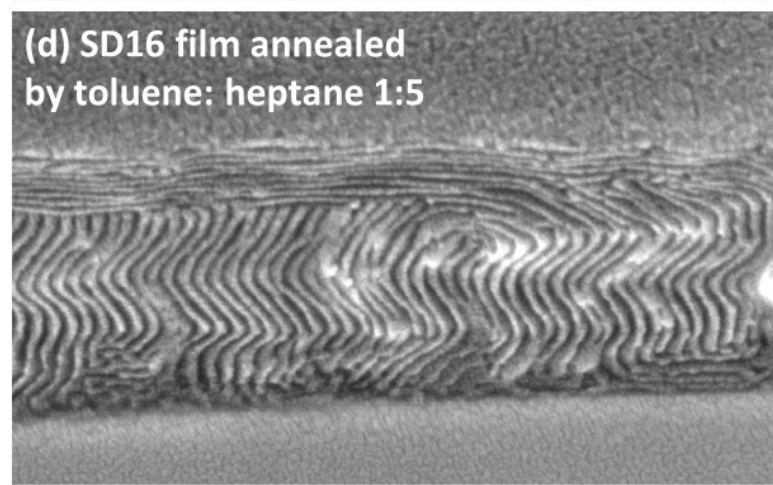

Figure 1. SEM of the final solvent-vapor annealed morphology of (a) SD16 film with as-cast thickness $210 \mathrm{~nm}$ using pure toluene vapor, Process (i); (b) SD16 film with as-cast thickness $231 \mathrm{~nm}$, using solvent vapor generated from reservoir of toluene: heptane 5:1 volumetric mixture, Process (ii); (c) SD12 film with as-cast thickness $208 \mathrm{~nm}$, using solvent vapor generated from reservoir of toluene: heptane 5:1 volumetric mixture, Process (iii). (d) SD16 film with as-cast thickness $400 \mathrm{~nm}$, using solvent vapor generated from reservoir of toluene: heptane 1:5 volumetric mixture, Process (iv). 

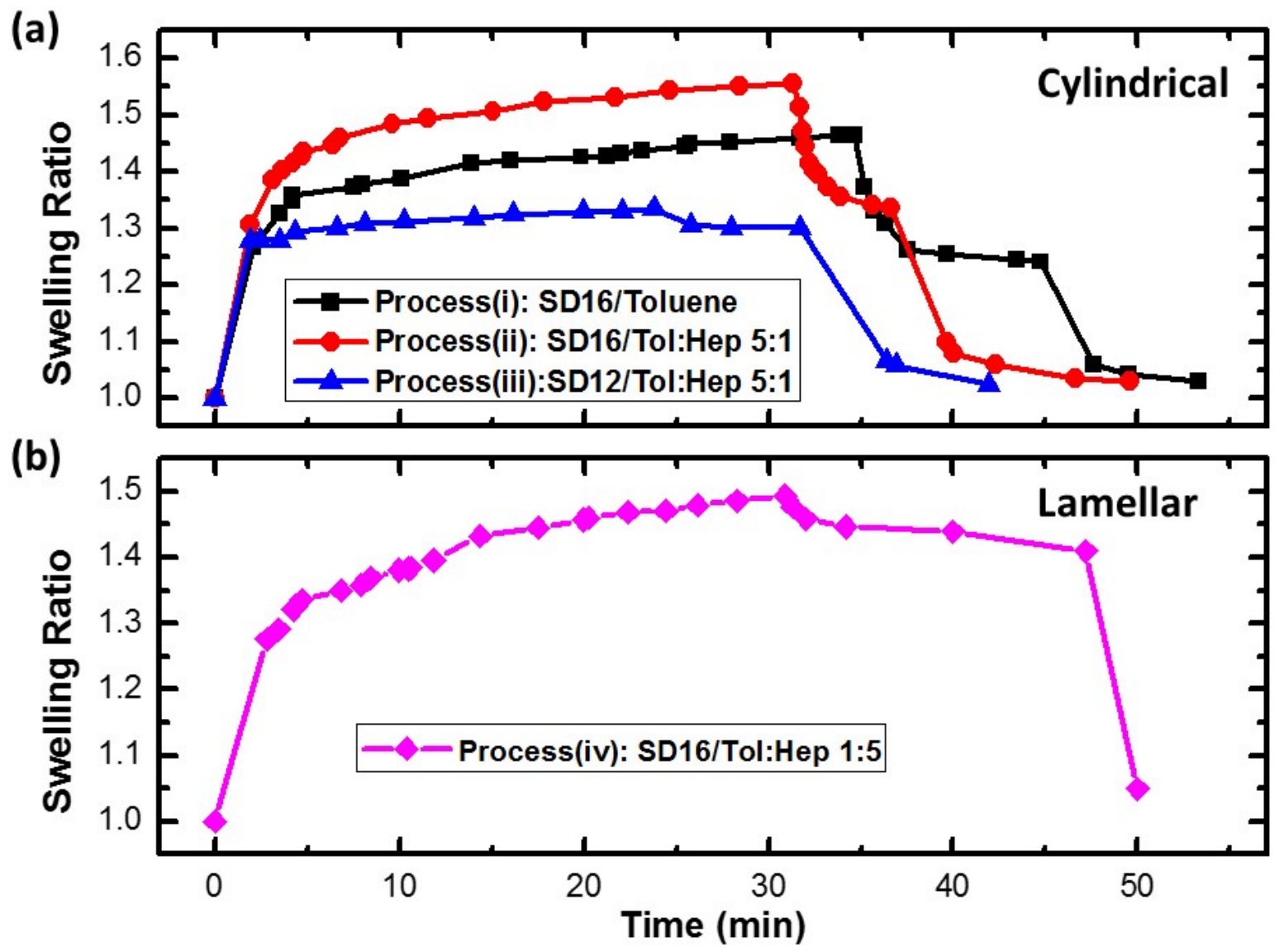

Figure 2. In Situ swelling ratio measurement on solvent vapor annealing of SD12 and SD16 PS- $b$-PDMS block copolymer thin films. (a) Process (i): SD16 film, with as-cast thickness $210 \mathrm{~nm}$, was annealed under pure toluene vapor; Process (ii): SD16 film, with as-cast thickness $231 \mathrm{~nm}$, was annealed under solvent vapor generated from reservoir of toluene: heptane 5:1 volumetric mixture. Process (iii): SD12 film, with as-cast thickness $208 \mathrm{~nm}$, was annealed under solvent vapor generated from reservoir of toluene: heptane 5:1 volumetric mixture. (b) Process (iv): SD16 film, with as-cast thickness $400 \mathrm{~nm}$, was annealed under solvent vapor generated from reservoir of toluene: heptane 1:5 volumetric mixture. The swelling ratio is the swelled film thickness divided by the as-cast film thickness. 


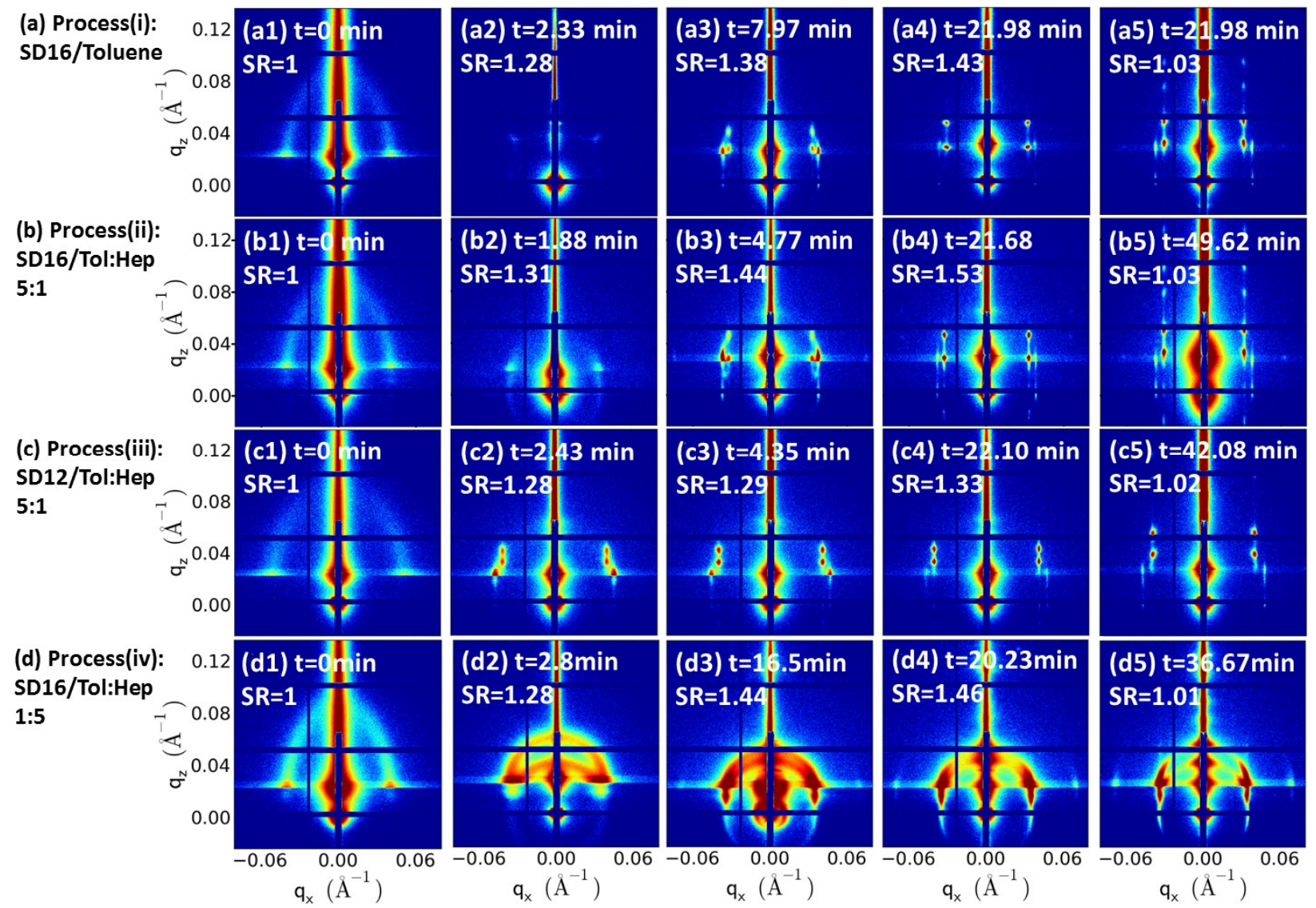

Figure 3. In Situ GISAXS fata for solvent vapor annealing of SD12 and SD16 PS- $b$-PDMS block copolymer thin films. (a) Process (i): SD16 film, with as-cast thickness $210 \mathrm{~nm}$, was annealed under pure toluene vapor; (b) Process (ii): SD16 film, with as-cast thickness $231 \mathrm{~nm}$, was annealed under solvent vapor generated from reservoir of toluene: heptane 5:1 volumetric mixture. (c) Process (iii): SD12 film, with as-cast thickness $208 \mathrm{~nm}$, was annealed under solvent vapor generated from reservoir of toluene: heptane 5:1 volumetric mixture. (d) Process (iv): SD16 film, with as-cast thickness $400 \mathrm{~nm}$, was annealed under solvent vapor generated from reservoir of toluene: heptane 1:5 volumetric mixture. t: annealing time (min); SR: swelling ratio (swelled film thickness divided by as-cast film thickness). 
(a)

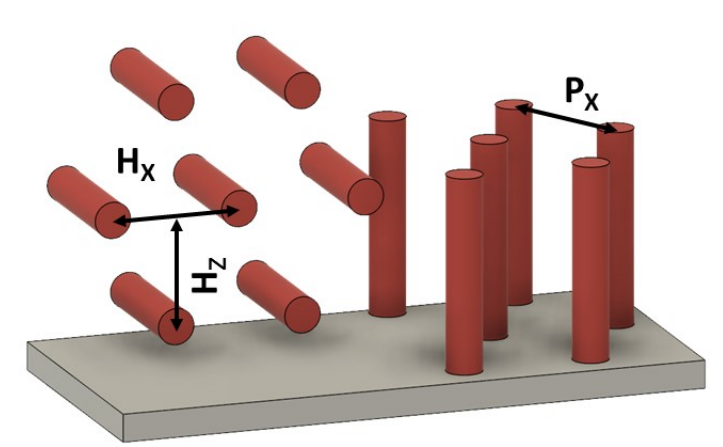

(b)

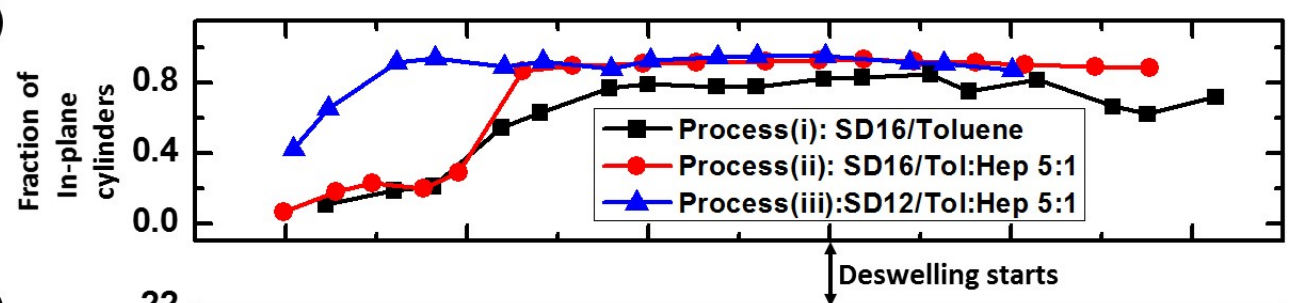

(c)

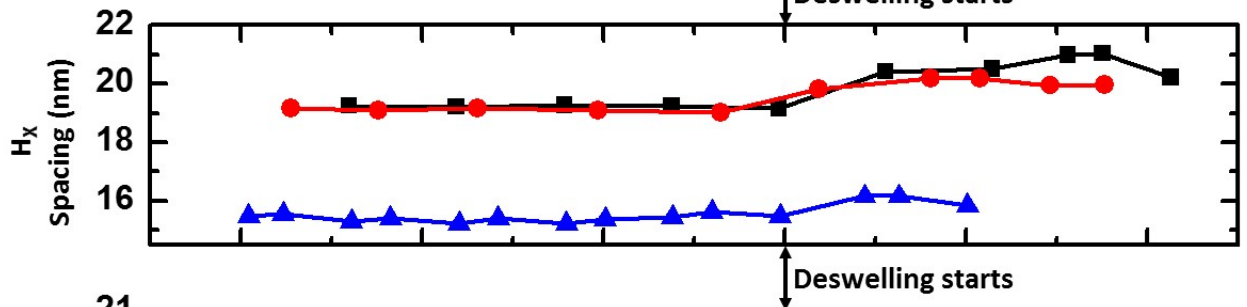

(d)

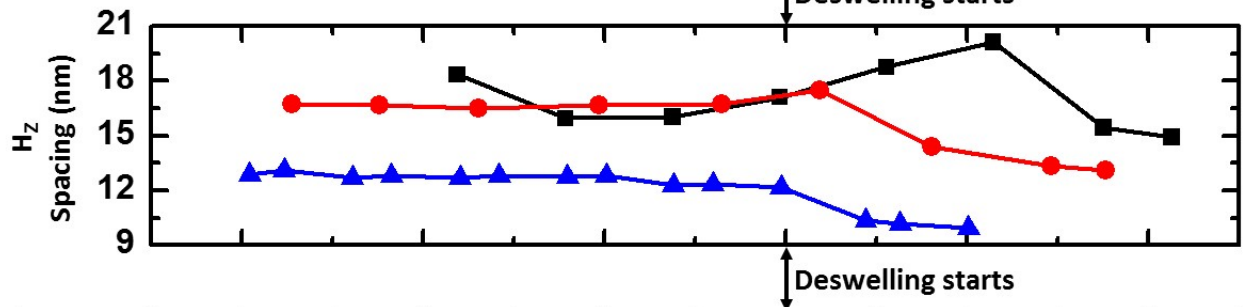

d)

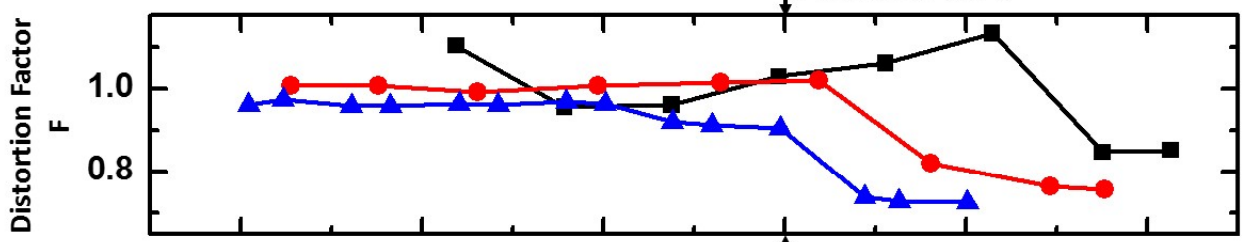

(e)

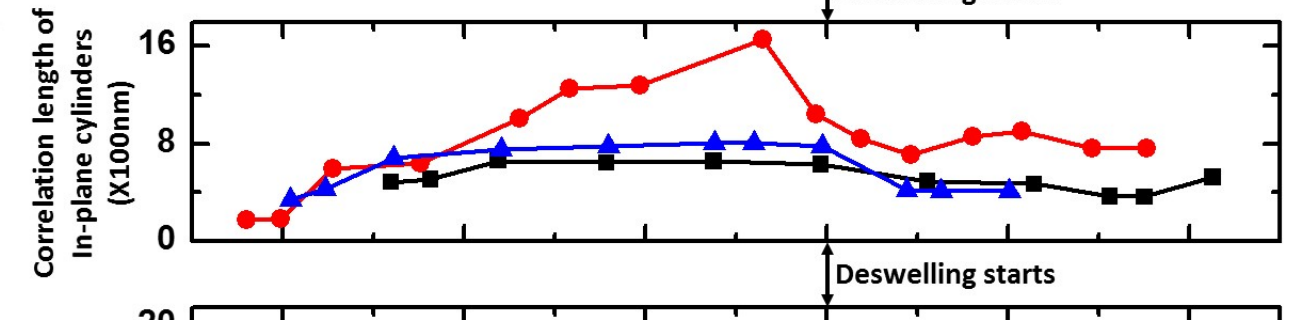

(f)

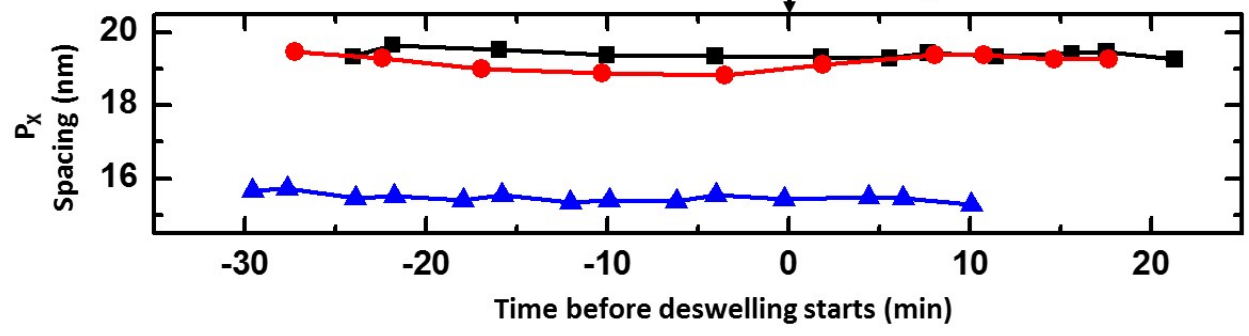


Figure 4. Quantitative analysis of evolution of fraction of in-plane cylinders, microdomain spacing, distortion factor, and correlation length as function of time for SD12 film and SD16 films under solvent vapor annealing. Top: Schematic plot of ideal hexagonal packing symmetry of in-plane and out-ofplane cylinders to define $\mathrm{H}_{\mathrm{x}}$ : the center-to-center distance within a layer of cylinders; $\mathrm{H}_{\mathrm{z}}$ : the out-ofplane distance between layers of cylinders; $P_{\mathbf{x}}$ : the center-to-center distance between adjacent out-ofplane cylinders. (a) Quantitative analysis of evolution of fraction of in-plane cylinders as function of time. (b) In situ measurement of $\mathrm{H}_{\mathrm{X}}$ of in-plane oriented cylinders for process (i)-(iii); (c) In situ measurement of $\mathrm{H}_{\mathrm{z}}$ of in-plane oriented cylinders for process (i)-(iii); (d) Calculated distortion factor (DF) of in-plane oriented cylinders for process (i)-(iii) based on in situ GISAXS measurement; $D F=$ $2 H_{Z} / \sqrt{3} H_{X}$. (e) In situ measurement of correlation length of in-plane cylinders for process (i)-(iii). (f) In situ measurement of $P_{x}$ for process (i)-(iii). Sweling ratios of process (i)-(iii) were indicated in Fig. 2. However, in this figure the time axis has been adjusted for each process to correspond to the time before deswelling.

(a)

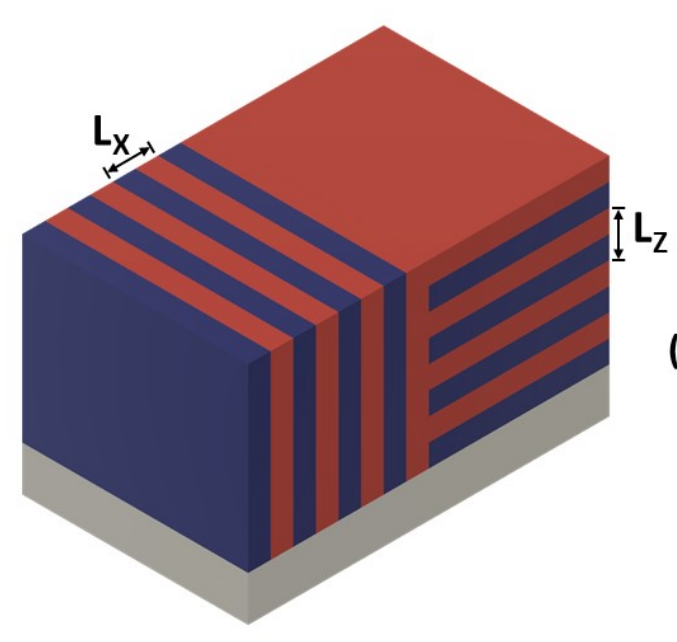

(b)

(c)

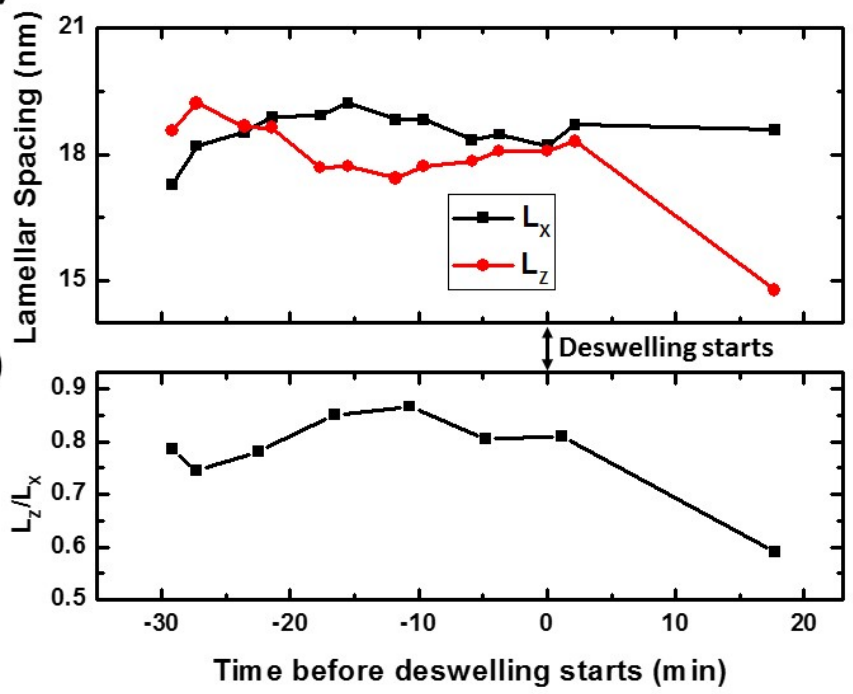

Figure 5. In Situ observation of non-bulk morphology solvent vapor annealing, Process (iv). (a) Schematic plot of self-assembled lamellar morphology to define $L_{x}$ : the periodicity of out-of-plane oriented lamellae; Lz: the periodicity of in-plane oriented lamellae. (b) Period of SD16 film with as-cast thickness $\mathbf{4 0 0} \mathrm{nm}$ during an anneal in vapor from a toluene: heptane 1:5 volumetric mixture for 50 mins, process (iv). The time film deswelling starts is indicated by an arrow on top of the plot. 